Article

\title{
Transferrin-Conjugated Docetaxel-PLGA Nanoparticles for Tumor Targeting: Influence on MCF-7 Cell Cycle
}

\author{
Sajan Jose ${ }^{1,2, *}$, Thomas A. Cinu ${ }^{1}$, Rosmy Sebastian ${ }^{1}$, M. H. Shoja ${ }^{3}$, N. A. Aleykutty ${ }^{4}$, \\ Alessandra Durazzo ${ }^{5}$, , Massimo Lucarini ${ }^{5}$, Antonello Santini ${ }^{6, *(1)}$ and Eliana B. Souto $2,7, * \mathbb{C}$ \\ 1 Department of Pharmaceutical Sciences, Mahatma Gandhi University, Cheruvandoor Campus, \\ Ettumanoor 686631, India; cinusaj@gmail.com (T.A.C.); rosmysebastian2009@gmail.com (R.S.) \\ 2 CEB-Centre of Biological Engineering, University of Minho, Campus de Gualtar, 4710-057 Braga, Portugal \\ 3 College of Pharmaceutical Sciences, Manipal University, Manipal 576104, India; shojamh@gmail.com \\ 4 Caritas College of Pharmacy, Kottayam 686630, India; aleykuttyna@gmail.com \\ 5 CREA-Research Centre for Food and Nutrition, Via Ardeatina 546, 00178 Rome, Italy; \\ alessandra.durazzo@crea.gov.it (A.D.); massimo.lucarini@crea.gov.it (M.L.) \\ 6 Department of Pharmacy, University of Napoli Federico II, Via D. Montesano 49, 80131 Napoli, Italy \\ 7 Department of Pharmaceutical Technology, Faculty of Pharmacy, University of Coimbra (FFUC), Pólo das \\ Ciências da Saúde, 3000-548 Coimbra, Portugal \\ * Correspondence: sajanjose@hotmail.com (S.J.); asantini@unina.it (A.S.); ebsouto@ebsouto.pt (E.B.S.); \\ Tel.: +91-9447600750 (S.J.); +39-081-253-9317 (A.S.); +351-239-488-400 (E.B.S.)
}

Received: 18 October 2019; Accepted: 15 November 2019; Published: 19 November 2019; Corrected: 30 December 2022

\begin{abstract}
Targeted drug delivery systems are commonly used to improve the therapeutic index of anti-cancer drugs by increasing their selectivity and reducing systemic distribution and toxicity. Ligand-conjugated nanoparticles (NPs) can be effectively applied for active chemotherapeutic targeting to overexpressed receptors of tumor cells. In this study, transferrin $(\mathrm{T} f)$ was successfully conjugated with poly-L-lactic-co-glycolic acid (PLGA) using ethylene diamine confirmed by NMR, for the loading of docetaxel trihydrate (DCT) into PLGA nanoparticles (NPs). The DCT-loaded Tf-conjugated PLGA NPs were produced by an emulsion-solvent evaporation technique, and a $3^{2}$ full factorial design was used to optimize the nanoparticle formulations. The DCT-loaded $\mathrm{T} f$-conjugated PLGA NPs were characterized by FTIR spectroscopy, differential scanning calorimetry, powder $X$-ray diffraction (PXRD), TEM, particle size, and zeta potential analysis. In vitro release kinetics confirmed that release of DCT from the designed formulations followed a zero-order kinetics and a diffusion controlled non-Fickian release profile. The DCT-loaded T $f$-conjugated PLGA NPs were evaluated in vitro in MCF-7 cells for bioactivity assessment. Cytotoxicity studies confirmed that the $\mathrm{T} f$-conjugated PLGA NPs were more active than the non-conjugated counterparts. Cell uptake studies re-confirmed the ligand-mediated active targeting of the formulated NPs. From the cell cycle analysis, the anti-cancer activity of DCT-loaded $\mathrm{T} f$-conjugated PLGA NPs was shown to occur by arresting the $\mathrm{G}_{2} / \mathrm{M}$ phase.
\end{abstract}

Keywords: transferrin conjugate; tumor targeting; docetaxel trihydrate; PLGA nanoparticles; factorial design

\section{Introduction}

Chemotherapy is traditionally used for cancer treatment; however, its therapeutic efficacy is usually limited by two major challenges. Firstly, there is the risk of occurrence of multidrug resistance (MDR) phenotypes leading to the unsuccess of chemotherapy. In fact, the major mechanism of MDR 
has been attributed to the MDR1 gene which codifies for the P-glycoprotein (P-gp) in cancer cells [1]. Secondly, chemotherapeutic drugs can unselectively enter into both healthy and tumor tissues, resulting in undesirable side effects and even death of the patients. Significant efforts have therefore been made to develop alternative therapies that improve the therapeutic index of anticancer drugs both by increasing their efficiency and decreasing their toxicity $[2,3]$.

In recent years, the design and synthesis of biocompatible and biodegradable nanoparticles have opened new perspectives for several biological and biomedical applications [4-9]. Among them, polymeric nanoparticles have emerged as promising carriers for targeting poorly water-soluble or amphiphilic drugs [4-6] as well as genes to tumor tissues [7,8]. The vasculature in tumors is leaky to macromolecules, and the tumor lymphatic system is usually deficient, thus nanoparticles (NPs) can preferentially be delivered into the tumor through the enhanced permeation and retention (EPR) effect via its blood vessels [9]. Still, it was found that polymeric NPs could reduce the multidrug resistance by a mechanism of internalization of the drug and reducing its efflux from cells mediated by P-gp $[10,11]$. However, it is of critical importance to develop a more specific and active delivery system that could target the tumor and enhance intracellular uptake of the drug to the tumor site. Selective interactions set between cancer cell receptors and specific targeting moieties decorating the surface of nanoparticles have been exploited. Some ligands, such as folate [12-15] and transferrin [16,17], can be conjugated to the polymer back-bone and substantially increase site-specific targeting of drug loaded NPs. A synergistic combination of dual-targeting ligands has also been proposed to enhance in vitro and in vivo tumor targeting [18].

The major challenge in the active targeting using nanoparticles is the development of drug/gene loaded nanoformulation containing a conjugated ligand or antibody. The complexity of the formulation development, stability of the formulation and difficulty in scaling up are the reasons for very little marketed products of this kind [19]. There is thus an urgent need for developing simpler and newer techniques for tumor targeted delivery of anticancer drugs. On the other side, clinical trials with nanomedicines, in Europe, have increased; studies on follow-up, use, and compliance, as reported by recent studies in the area [20-22] as well as communication strategies and assessment $[23,24]$ are needed.

In this study, we propose a novel approach based on transferrin (Tf)-conjugated poly(lactide-co-glycolide) (PLGA) nanoparticles loaded with docetaxel trihydrate (DCT) for tumor targeting. Poly(lactide-co-glycolide) (PLGA) was selected as a polymer matrix because it is a biodegradable copolymer widely used in many Food and Drug Administration (FDA)-approved drug formulations. The PLGA-NPs have also been reported to be appropriate for the loading or poorly water-soluble drugs for parenteral and ocular administration [4-6,25-30]. The glycoprotein transferrin was selected as a ligand because it is upregulated on the surface of cancer cells. The increased iron requirement in cancer cells results in higher expression of transferrin receptors in these cells compared to the normal ones. Docetaxel trihydrate (DCT) is a second generation taxane derived from a compound found in the European yew tree Taxus baccata [31]. The drug is practically insoluble in water and is being currently used in chemotherapy of gastro/esophageal [32-36] and breast [37-40] cancers. It binds precisely to the $\beta$-tubulin subunit of microtubules and antagonizes the disassembly of this key cytoskeletal protein, with the result that bundles of microtubules and aberrant structures, derived from the microtubules, appear in the mitotic phase of the cell cycle. Arrest in the mitosis follows.

We report for the first time the use of a $3^{2}$ full factorial design for the optimization of Tf-conjugated PLGA NPs for the loading of DCT, produced by a modified oil-in-water $(\mathrm{o} / \mathrm{w})$ emulsion solvent evaporation technique $[29,41]$. The factorial design generally depends on first degree mathematical models. Full factorial designs involve studying the effect of all the factors at various levels, including the interactions among them. The mathematical model associated with the design consists of the main effects of each variable plus all the possible interaction effects among factors in the model [42]. The PLGA-EDA-transferrin conjugate was synthesized according to a procedure optimized in our lab. 
The release profile has also been characterized using several mathematical models, namely, zero- and first-order kinetics, Higuchi, and Korsmeyer-Peppas.

\section{Materials and Methods}

\subsection{Chemicals}

Docetaxel trihydrate was obtained as a gift sample from Mac Chem Products Pvt Ltd. (Mumbai, India). The PLGA (50:50), polyvinyl alcohol (PVA), coumarin-6, and human transferrin (T $f$ ) were purchased from Sigma-Aldrich (Bangalore, India). Dichloromethane (DCM), ethylene diamine, and dimethyl sulfoxide (DMSO) were purchased from Merck Chemicals (Mumbai, India). N-Hydroxy succinimide (NHS) and 1-ethyl-3(3-dimethyl aminopropyl) carbodiimide (EDC) were purchased from Himedia (Mumbai, India). All other reagents used were of analytical grade and home supplied.

\subsection{Synthesis of PLGA-EDA-Transferrin Conjugate and NMR Analysis}

Prior to the production of nanoparticles, the PLGA-EDA-transferrin conjugate was synthesized according to Figure 1. The selected proportions of reactants were based on preliminary studies to optimize the total use of ligand in the produced number of nanoparticles.
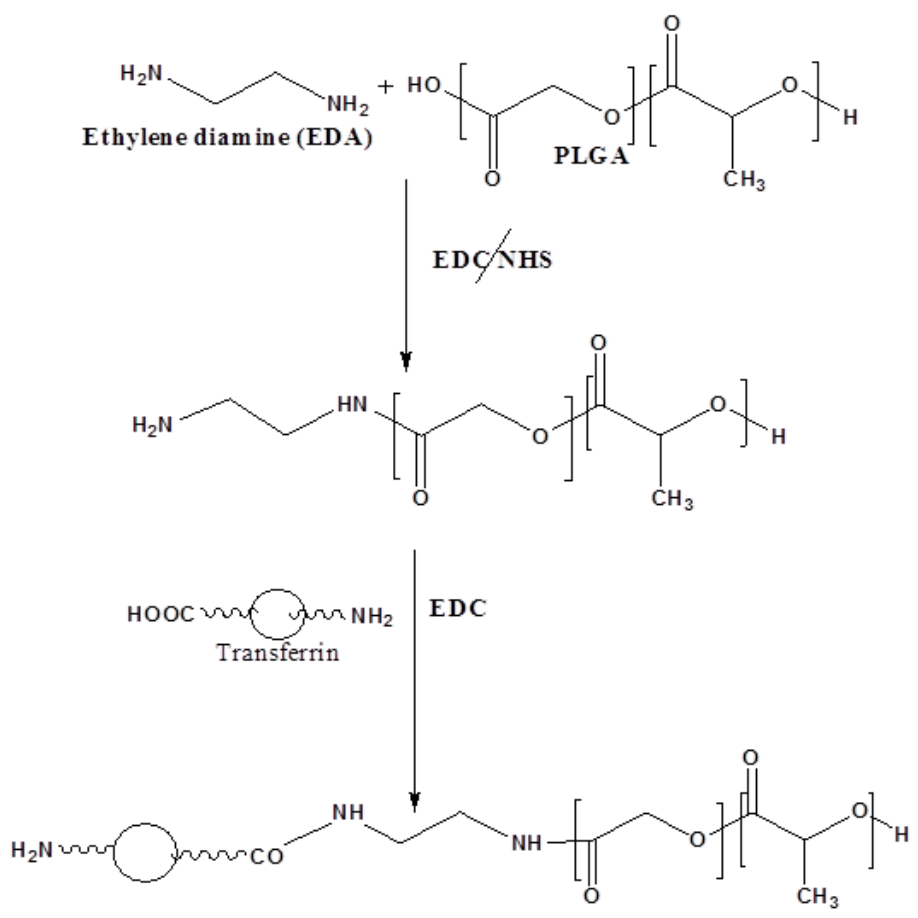

Figure 1. Synthesis of the poly(lactide-co-glycolide) (PLGA)-EDA-transferrin conjugate.

A solution of PLGA (0.01 mmol), 1-ethyl-3-(dimethylaminopropyl) carbodiimide (EDC) $(0.08 \mathrm{mmol})$, and $\mathrm{N}$-hydroxysuccinimide (NHS) $(0.08 \mathrm{mmol})$ was prepared in a round-bottom flask using anhydrous DCM as solvent and left to stir overnight. The obtained solution was then filtered and added to cold anhydrous ether dropwise to allow the precipitation of activated PLGA. Ether was removed by decantation and the obtained polymer was then dried overnight under vacuum to obtain the solid activated PLGA. The obtained solid activated polymer $(0.01 \mathrm{mmol})$ was dissolved in $8 \mathrm{~mL}$ anhydrous DCM in a round-bottom flask. An amount of $0.05 \mathrm{mmol}$ of ethylene diamine EDA was dissolved in $2 \mathrm{~mL}$ anhydrous DCM and added to the freshly prepared polymeric solution. The mixture was then gently stirred at $400 \mathrm{rpm}$ under nitrogen atmosphere for $6 \mathrm{~h}$. The reaction mixture was added dropwise to cold anhydrous ether to precipitate the product which was dried under vacuum. To wash the un-reacted EDA, the product was dissolved in DMSO and transferred into a dialysis 
bag. The content of the bag was dialyzed against $5 \mathrm{~L}$ of de-ionized water for $48 \mathrm{~h}$ at $4{ }^{\circ} \mathrm{C}$ with constant stirring at $600 \mathrm{rpm}$ (with 4 changes). The obtained dispersion was freeze-dried and stored at a temperature of $-20^{\circ} \mathrm{C}$. Transferrin $(0.00125 \mathrm{mmol})$ was activated with EDC $(0.0025 \mathrm{mmol})$ and NHS $(0.0025 \mathrm{mmol})$ using anhydrous DMSO in the presence of triethylamine $(0.1 \mathrm{~mL})$, under atmosphere protected from light. The by-product, dicyclohexylurea, was removed by filtering the solution and activated transferrin was precipitated in cold anhydrous ether. The product was washed several times, decanted, and dried. Activated Tf, EDC $(0.006 \mathrm{mmol})$ and PLGA-EDA $(0.024 \mathrm{mmol})$ were co-dissolved in anhydrous DMSO in light protected conditions for $8 \mathrm{~h}$. The EDC was added to ensure that all the transferrin is ready to react with PLGA-EDA. An excess amount of activated transferrin was used to achieve a higher conjugation of $\mathrm{T} f$ to PLGA-EDA. The obtained product was filtered, precipitated using methanol as solvent, followed by drying under vacuum. To precipitate free un-reacted transferrin, the dried product was dissolved in DCM, followed again by filtration. The organic solvent (DCM) present in the solution was then removed by evaporation under vacuum. The obtained product was analyzed by proton NMR spectroscopy on a Bruker AV 400-400 MHz High resolution Multinuclear FT-NMR spectrometer (Bruker BioSpin, Rheinstetten, Germany).

\subsection{Formulation of Drug-Loaded Nanoparticles Using Polymer Conjugates}

The transferrin ( $\mathrm{T} f$ ) conjugate PLGA nanoparticles loaded with docetaxel trihydrate (DCT-Tf-PLGA NPs) were prepared by a modified oil-in-water $(\mathrm{o} / \mathrm{w})$ emulsion solvent evaporation technique [43]. The ligand conjugated polymer was accurately weighed and dissolved in dichloromethane (DCM) and $5 \mathrm{mg}$ drug in $0.1 \mathrm{~mL}$ DMSO. Drug solution was added with gentle stirring to the polymer solution to dissolve the contents. This organic phase was added slowly to aqueous phase containing poly vinyl alcohol (PVA) as stabilizer and sonicated using a probe sonicator (Sonics Vibracell, USA) at an output of $40 \mathrm{~W}$ in an ice bath. The o/w emulsion formed was gently stirred at room temperature by a magnetic stirrer (Tarson, Mumbai, India) for up to $12 \mathrm{~h}$ for complete evaporation of organic solvent. The resulting suspension was centrifuged at $15,000 \mathrm{rpm}$ for $20 \mathrm{~min}$ at $4{ }^{\circ} \mathrm{C}$ to separate the nanoparticles. The particles were washed with distilled water, thrice, to remove the emulsifier and adsorbed drug molecules. Then, particles were freeze-dried for $24 \mathrm{~h}$ using a lyophilizer (Sub-Zero, Chennai, India) at $-85^{\circ} \mathrm{C}$ and 0.001 mbar pressure.

\subsection{Optimization of the Formulation Process}

The DCT-loaded T $f$-conjugated PLGA NPs of desired quality is affected by different factors. Optimizing these factors by trial and error method is tedious and costly. Design of experiments (DoE) was therefore applied for the optimization of the process of nanoparticle formulation with the help of Design Expert ${ }^{\circledR}$ ver. 8.0.7.1 software (Statease, Minneapolis, USA). A two-factor three-level full factorial design was used in the optimization of nanoparticles for the study of the influence of the two independent variables on the responses $\left(Y_{1}\right.$ and $\left.Y_{2}\right)$ particle size and percentage of encapsulated drug. The DoE was therefore appropriate for the study of the quadratic surface responses and for the construction of the second order polynomial models. After measuring the responses with either simple linear $\left(\mathrm{Y}=\mathrm{X}_{0}+\mathrm{X}_{1} \mathrm{~A}+\mathrm{X}_{2} \mathrm{~B}\right)$, interactive $\left(\mathrm{Y}=\mathrm{X}_{0}+\mathrm{X}_{1} \mathrm{~A}+\mathrm{X}_{2} \mathrm{~B}+\mathrm{X}_{5} \mathrm{AB}\right)$ or quadratic $\left(\mathrm{Y}=\mathrm{X}_{0}+\mathrm{X}_{1} \mathrm{~A}+\mathrm{X}_{2} \mathrm{~B}\right.$ $\left.+X_{3} A_{2}+X_{4} B_{2}+X_{5} A B+E\right)$ models, the values of selected variables at different levels can be obtained by multiple regression analysis of the data and $\mathrm{F}$ statistics to identify the statistically significant terms. The reduced equation (i.e., an equation based solely on statistically significant terms) is then used for drawing contour plots to evaluate the influence of selected variables when changing from low to high level. The non-linear quadratic model generated by the design is in the form $\mathrm{Y}=\mathrm{X}_{0}+\mathrm{X}_{1} \mathrm{~A}+$ $\mathrm{X}_{2} \mathrm{~B}+\mathrm{X}_{3} \mathrm{~A}_{2}+\mathrm{X}_{4} \mathrm{~B}_{2}+\mathrm{X}_{5} \mathrm{AB}+\mathrm{E}$, where $\mathrm{Y}$ is the measured response associated with each factor level combination: $X_{0}$ is an intercept; $X_{1}-X_{5}$ are the regression coefficients; $A$ and $B$ are the factors studied; and $\mathrm{E}$ is the associated error term.

Based on the pre-optimization studies, three square full factorial designs were selected for optimization. The phase ratio and sonication time were found to have significant effect on particle 
size and encapsulation efficiency. The design matrix was fixed, and three levels were chosen based on the data from the pre-optimization. While the success of the formulation depends on the particle size and encapsulation efficiency, these were therefore chosen as the responses. The three-square design matrix and the factors with their levels are shown in Table 1. The responses (i.e., particle size and encapsulation efficiency) were statistically evaluated using Design Expert 8.0.7.1 software (Stat-Ease Inc., Minneapolis, USA).

Table 1. Factors and levels used in the design of experiments.

\begin{tabular}{cccc}
\hline \multirow{2}{*}{ Independent Variables } & \multicolumn{3}{c}{ Levels } \\
\cline { 2 - 4 } & $\mathbf{- 1}$ & $\mathbf{0}$ & $\mathbf{+ 1}$ \\
\hline Phase ratio & $1: 3$ & $1: 4$ & $1: 5$ \\
Sonication time (min) & 6 & 8 & 10 \\
Dependent variables & \multicolumn{3}{c}{$\mathrm{Y}_{1}$-Mean Particle Size } \\
& \multicolumn{2}{c}{$\mathrm{Y}_{2}$-Encapsulation Efficiency (EE\%) } \\
\hline
\end{tabular}

\subsection{Determination of Encapsulation Efficiency and Drug Loading Capacity}

The encapsulation Efficiency (EE\%) and the loading capacity were determined by a direct method. Briefly, accurately weighed $5 \mathrm{mg}$ of the freeze-dried nanoparticles were vortexed with $2 \mathrm{~mL}$ of DCM for $1 \mathrm{~h}$ and filtered through $0.22 \mu \mathrm{m}$ membrane filter. The drug content in the filtrate was then analyzed by HPLC. The percentage of drug encapsulation, a measure of the encapsulation efficiency, was calculated as the ratio of the drug content in the freeze-dried powder and the initial drug amount added for the production [29]. The drug loading capacity was determined as the ratio of the drug content to the freeze-dried powder.

$$
\begin{aligned}
& \text { Encapsulation efficiency }(\%)=\frac{\text { Loaded drug }}{\text { Total drug added }} \times 100 \\
& \text { Loading capacity }(\%)=\frac{\text { Loaded drug }}{\text { Total amount of polymer }} \times 100
\end{aligned}
$$

\subsection{Fourier Transform Infrared Spectroscopy (FTIR)}

The FTIR was used to analyze freeze-dried DCT-loaded Tf-conjugated PLGA NPs to study the chemical properties of docetaxel trihydrate and drug-loaded nanoparticles by functional group analysis. The samples were analyzed by an FTIR Spectrum 400 analyzer (Perkin Elmer, Massachusetts, USA) and reported in wave number $\left(\mathrm{cm}^{-1}\right)$. The scanning range was $400-4000 \mathrm{~cm}^{-1}$.

The FTIR spectroscopy can be defined as a "fingerprint analytical technique" for the structural identification of compounds considering that no two chemical structures will have the same FTIR spectrum. The FTIR provides a characteristic signature of chemical or biochemical substances present in the sample by featuring their molecular vibrations (stretching, bending, and torsions of the chemical bonds) in specific infrared regions [44].

\subsection{Differential Scanning Calorimetry (DSC)}

Differential scanning calorimetry was used to analyze bulk PLGA, transferrin, docetaxel trihydrate, and their physical mixture as well as the freeze-dried DCT-loaded Tf-conjugated PLGA NPs to compare the thermograms. The analysis was carried out in a DSC from TA Instruments (MDSC 2910, USA).

\subsection{Powder X-ray Diffraction (PWRD)}

Powder X-ray diffraction patterns of bulk PLGA, transferrin, docetaxel trihydrate, and their physical mixtures as well as the freeze-dried DCT-loaded Tf-conjugated PLGA NPs were compared to 
study the change in crystal structure using X-ray diffractometer X'pert PRO, (PANalytical, Almelo, The Netherlands).

\subsection{Transmission Electron Microscopy (TEM)}

Transmission electron microscopy was used to obtain more detailed surface images of nanoparticles. Analysis was performed in a JEOL JEM-1010 electron microscope (JEOL Ltd., Tokyo, Japan). The nanoparticles were suspended in Milli-Q water. A tiny drop of sample was pipetted onto the parafilm using a micropipette, placing the shiny side of the TEM grid on the drop and left for $20 \mathrm{~min}$ for the particles to adsorb onto the grid. The grid was then removed and placed on a tissue paper (Kimwipe without fibers) with the shining side up for $1 \mathrm{~h}$ for drying. Image scanning of the sample was performed under different magnifications.

\subsection{Mean Particle Size, Size Distribution, and Zeta Potential}

The mean particle size, size distribution, and zeta potential $(\mathrm{ZP})$ of the optimized surface-modified nanoparticles were determined by dynamic light scattering technique using Zetasizer Nano ZS, nanoseries, Malvern Instruments, MA, USA). A concentration of $0.1 \%$ by weight of the sample was prepared in phosphate buffered solution (PBS) of $\mathrm{pH} 7.4$ for zeta potential measurement.

\subsection{In Vitro Drug Release Studies}

The drug release profile of docetaxel from PLGA nanoparticles was studied using a dialysis technique. Briefly, a mass of freeze-dried nanoparticles equivalent to $5 \mathrm{mg}$ of docetaxel was weighted, dispersed in $1 \mathrm{~mL}$ of phosphate buffer solution at $\mathrm{pH} 7.4$ and placed in a dialysis bag (Spectra/Por ${ }^{\circledR}$, molecular weight cut-off $12,000 \mathrm{Da}$ ). The dialysis bag was sealed at both ends, soaked in $100 \mathrm{~mL}$ of phosphate buffer solution ( $\mathrm{pH} 7.4$ ), and maintained at $37 \pm 0.5^{\circ} \mathrm{C}$ and at $100 \pm 5 \mathrm{rpm}$ in a shaker. Sampling volumes were taken at predetermined time intervals, being replaced by the same volume of fresh phosphate buffer solution to keep sink conditions. The amount of docetaxel trihydrate released into the medium was quantified by HPLC and compared to a generated standard calibration curve [45]. The experiment was done in triplicate and results are expressed as the mean and standard deviation.

\subsection{In Vitro Bioactivity Studies}

The cytotoxicity of nanoparticles was evaluated using the MTT assay in MCF-7 cells. The MCF-7 cells (human breast cancer cell line) were obtained from NCCS Pune, India. Cells were grown in $25 \mathrm{~cm}^{2}$ tissue culture flasks containing Dulbecco's modified Eagle's medium (DMEM) supplemented with $10 \%$ FBS, $1 \%$ L-glutamine, and $50 \mu \mathrm{g} / \mathrm{mL}$ gentamycin sulphate. Cell uptake studies were carried out with coumarin-6-tagged nanoparticles by flow cytometric determination [46] and cell cycle analysis was also done with MCF-7 cells by flow cytometry [47,48].

\subsubsection{MTT (3-(4, 5-Dimethylthiazol-2-yl)-2, 5-Diphenyltetrazolium Bromide) Assay}

Exponentially growing cell lines were harvested from a $25 \mathrm{~cm}^{2}$ tissue culture flask, and a stock cell suspension $(5 \times 104 \mathrm{cell} / \mathrm{mL})$ was prepared. A 96 well flat bottom tissue culture plate was seeded with $5 \times 103$ cells in $0.1 \mathrm{~mL}$ of DMEM supplemented with 10\% FBS and allowed to attach for $24 \mathrm{~h}$. Test formulations were freshly prepared prior to the experiment and serially diluted with medium to obtain the desired concentrations. After $24 \mathrm{~h}$ of incubation, cells were treated with $100 \mu \mathrm{L}$ of test formulation and incubated for $24 \mathrm{~h}$. Each treatment was performed in triplicate. At the end of each experiment, medium was removed and washed with $200 \mu \mathrm{L}$ of PBS. To each 96 well plate, $100 \mu \mathrm{L}$ of MTT reagent (stock: $1 \mathrm{mg} / \mathrm{mL}$ in serum free medium) was added and incubated at $37^{\circ} \mathrm{C}$ for $4 \mathrm{~h}$. After $4 \mathrm{~h}$ of incubation, the plate was blotted on tissue paper to remove the MTT reagent. To solubilize formazan crystals in the wells, $100 \mu \mathrm{L}$ of $100 \%$ DMSO was added to each well, and the optical density was measured at $540 \mathrm{~nm}$. 


\subsubsection{Estimation of Coumarin-6 Tagged Nanoparticles Uptake by Flow Cytometry}

The MCF-7 $\left(1 \times 10^{6}\right)$ cells were seeded in 96 well plates and incubated at $37^{\circ} \mathrm{C}$ for $24 \mathrm{~h}$ in a humidified $\mathrm{CO}_{2}$ incubator. After $24 \mathrm{~h}$ of incubation, the medium was aspirated from the plates, and cells were washed with DMEM. A volume of $10 \mu \mathrm{L}$ of nanoparticles conjugated with coumarin-6 (at their respective $\mathrm{IC}_{50}$ concentrations) were incubated at $37^{\circ} \mathrm{C}$ in the $\mathrm{CO}_{2}$ incubator (for $2 \mathrm{~h}$ and $24 \mathrm{~h}$ ). The formulation in the medium was then aspirated, cells were washed thrice with PBS and scraped in $1 \mathrm{~mL}$ of fresh PBS using a cell scraper. The cells were analyzed using Accuri C6 flow cytometer (BD Biosciences, San Jose, CA, USA) excitation at $488 \mathrm{~nm}$ and emission at 533/30. A minimum of 10,000 events were recorded and analysis of flow cytometric data was performed using BD software. The first gating was done for a single cell population selection on a forward (FSS) versus side scatter (SSC) dot plot. The second dot plot was FL-1-A versus FL-4-A (533/30 versus 675/25) for selection of coumarin-6 fluorescence in the FL-1 channel. Plain normal cells were used for the normalization of the internal fluorescence or auto-fluorescence. The shift in mean fluorescence in FL1-A versus count plot was calculated [48].

\subsubsection{Cell Cycle Analysis}

The MCF-7 $\left(1 \times 10^{6}\right)$ cells were seeded in $25 \mathrm{~cm}^{2}$ flasks and after overnight adherence, incubated for $24 \mathrm{~h}$ with test formulations at their respective $\mathrm{IC}_{50}$ concentrations. Trypsinization was used to detach the cells followed by mixing with floating cells, centrifuged and PBS washed. The obtained cell pellets were fixed in $70 \%$ ice-cold methanol for $24 \mathrm{~h}$ at $-20{ }^{\circ} \mathrm{C}$. Cell pellets were washed with PBS and isotonic PI solution ( $25 \mu \mathrm{g} / \mathrm{mL}$ propidium iodide, $0.03 \% \mathrm{NP}-40$ and $40 \mu \mathrm{g} / \mathrm{mL}$ RNase A) was added. The Accuri C6 flow cytometer (BD Biosciences, San Jose, CA, USA) was used for the analysis of stained cells, applying $488 \mathrm{~nm}$ excitation and emission at 575/40 nm. A minimum of 10,000 events were recorded for each sample, and data analysis was done using BD Accuri ${ }^{\mathrm{TM}}$ C6 software $[49,50]$.

\section{Results and Discussion}

The PLGA-EDA-transferrin conjugate was synthesized according to the procedure optimized in our lab (Figure 1). The carboxy-terminal end group of PLGA was activated with 1-ethyl-3-EDC and linked to n-boc-ethylenediamine via an amide bond which was then de-protected to obtain PLGA-EDA with a free amine group. The water-soluble carbodiimide heterobifunctional crosslinker EDC is commonly used to couple carboxyl groups to primary amines. The ${ }^{1} \mathrm{H}$ and ${ }^{13} \mathrm{C}$ NMR are commonly used for the characterization of new compounds. In this work, we used ${ }^{1} \mathrm{HNMR}$ for which the spectra of PLGA and PLGA-EDA-transferrin are shown in Figure 2.

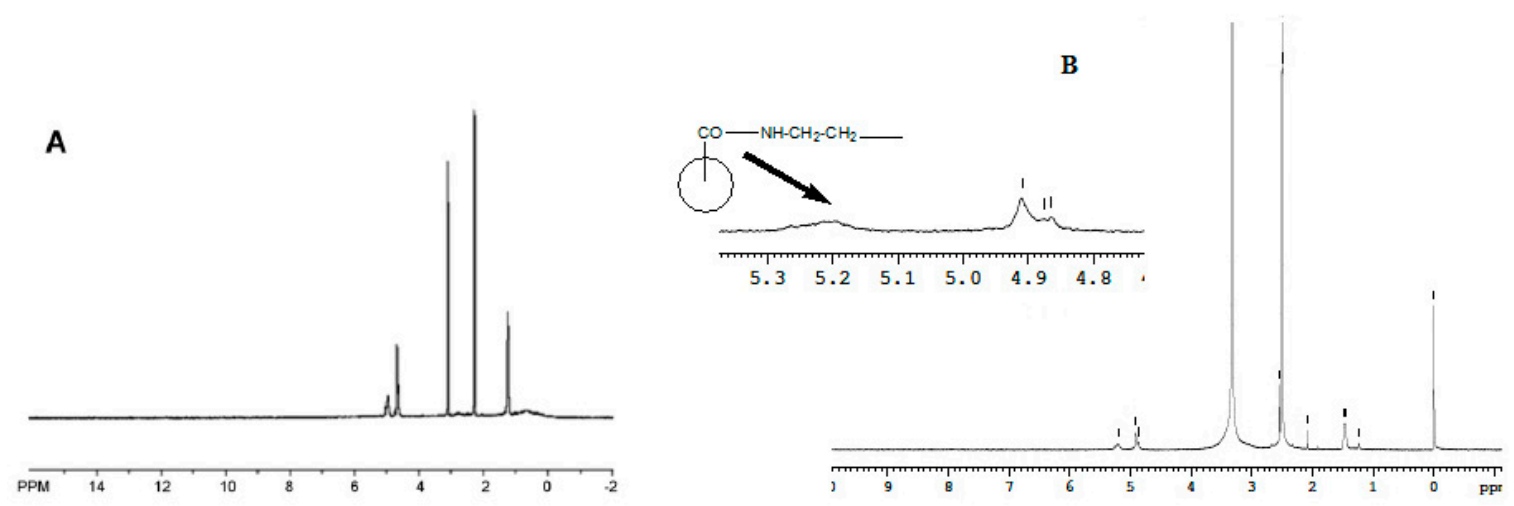

Figure 2. (A) ${ }^{1} \mathrm{H}$ NMR spectrum of PLGA (B). ${ }^{1} \mathrm{H}$ NMR spectrum of transferrin-conjugated PLGA-EDA.

The characteristic peaks confirming the successful conjugation were found in the ${ }^{1} \mathrm{HNMR}$ spectra of PLGA-EDA-transferrin conjugate. In Figure 2B, the peaks from 1.23 to $1.47 \mathrm{ppm}$ were attributed to methyl hydrogens $\left(-\mathrm{CH}_{3}\right)$ of PLGA segments, identified as $\left({ }^{(}\right)$. The peaks at 4.86 and 4.91 (identified as 
$\left.{ }^{(}\right)$in Figure 2B) were assigned to protons of hydroxyl and methine groups, respectively. The peaks at $2.541 \mathrm{ppm}$ and 2.501 (identified as $\left({ }^{\prime}\right)$ in Figure 2B) belonged to the methylene hydrogen groups of EDA and transferrin segments. Although weak, the peak recorded at 5.2 confirmed the -CONH- bond formation between the C-terminal of transferrin and $-\mathrm{NH}_{2}$ group of EDA (Figure 2B). The recorded spectrum demonstrates the successful conjugation of PLGA, EDA, and transferrin.

The procedure selected for the production of transferrin-conjugated PLGA nanoparticles was based on the solubility properties of docetaxel trihydrate. A modified oil-in-water $(\mathrm{o} / \mathrm{w})$ emulsion solvent evaporation technique was used, based on the emulsification of an organic solution of polymer in dichloromethane (DCM) (containing $5 \mathrm{mg}$ drug in $0.1 \mathrm{~mL}$ DMSO) in an aqueous phase followed by evaporation of the organic phase. The DCT was practically insoluble in water but showed approximately $5 \mathrm{mg} / \mathrm{mL}$ solubility in DMSO being therefore retained in the inner phase of the emulsion. The o/w emulsion was produced by processing the inner phase in the outer phase by high-shear homogenization. The organic phase was evaporated by stirring overnight in a magnetic stirrer. The nanoparticles were collected by ultracentrifugation and washed with Milli-Q water to remove any surfactant or free drug. The resulting nanoparticles were lyophilized to obtain free flowing drug-loaded PLGA nanoparticles. The PLGA NPs showed superior advantages over other drug carriers (e.g., liposomes, solid lipid nanoparticles), as the poorly water-soluble drug can be covalently linked to the carrier (as demonstrated in Figure 1).

Three square design is a two-factor three-level design, originating 13 runs that were used in this experiment. The two factors selected were the phase ratio and sonication time. An organic-to-aqueous ratio of 1:4 and sonication time of 8 min were selected as the central point in the $3^{2}$ full factorial design. Based on the results obtained during pre-formulation testing, the amount of docetaxel trihydrate in the formulation was fixed as $5 \mathrm{mg}$ and of ligand-conjugated polymer as $10 \mathrm{mg}$. The sonication amplitude was kept at $40 \mathrm{~W}$. The effect of the independent variables (phase ratio and sonication time) on the mean particle size and EE\% of the 13 produced PLGA NPs is given in Table 2.

Table 2. The effect of the chosen independent variables (factors) on the dependent variables (mean particle size and encapsulation efficiency). Loading capacities were also calculated for the 13 formulations.

\begin{tabular}{|c|c|c|c|c|c|}
\hline \multirow{2}{*}{ Formulation Code } & \multirow{2}{*}{$\begin{array}{c}\text { Factor } 1 \\
\text { Phase Ratio }\end{array}$} & \multirow{2}{*}{$\begin{array}{c}\text { Factor } 2 \\
\text { Sonication } \\
\text { Time (min) }\end{array}$} & \multirow{2}{*}{$\begin{array}{c}\text { Response } 1 \\
\text { Mean Particle } \\
\text { Size (nm) }\end{array}$} & \multicolumn{2}{|c|}{ Response 2} \\
\hline & & & & $\% E^{*}$ & $\%$ LC \\
\hline 1-Tf-PLGA NPs & $1: 4$ & 6 & 283.4 & 50 & 25.0 \\
\hline 2-Tf-PLGA NPs & $1: 4$ & 8 & 280.6 & 45.6 & 22.8 \\
\hline 3-Tf-PLGA NPs & $1: 5$ & 10 & 204.2 & 32.1 & 16.1 \\
\hline 4-Tf-PLGA NPs & $1: 4$ & 10 & 235.5 & 39.6 & 19.8 \\
\hline 5-Tf-PLGA NPs & $1: 5$ & 6 & 230.5 & 38.4 & 19.2 \\
\hline 6-Tf-PLGA NPs & $1: 4$ & 8 & 240.6 & 44.4 & 22.2 \\
\hline 7-Tf-PLGA NPs & $1: 4$ & 8 & 250.2 & 43.6 & 21.8 \\
\hline 8-Tf-PLGA NPs & $1: 4$ & 8 & 247.0 & 44.8 & 22.4 \\
\hline 9-Tf-PLGA NPs & $1: 5$ & 8 & 219.7 & 36.8 & 18.4 \\
\hline 10-Tf-PLGA NPs & $1: 4$ & 8 & 247.8 & 42.8 & 21.4 \\
\hline 11-Tf-PLGA NPs & $1: 3$ & 8 & 370.8 & 56.8 & 28.4 \\
\hline 12-Tf-PLGA NPs & $1: 3$ & 6 & 426.7 & 59.6 & 29.8 \\
\hline 13-Tf-PLGA NPs & $1: 3$ & 10 & 311.0 & 53.6 & 26.8 \\
\hline
\end{tabular}

* \%EE, percentage of encapsulation efficiency was used as the dependent variable in the factorial design experiment.

Thirteen formulations (1-Tf-PLGA NPs to 13-Tf-PLGA NPs) were prepared according to the set of experiments defined in the design matrix (Table 1). Polynomial equations for the individual main effects and interaction factors were obtained for each of the individual responses (mean particle size and $\mathrm{EE} \%$ ) based on the multiple correlation coefficient $\left(\mathrm{R}^{2}\right)$, adjusted multiple correlation coefficient (adjusted $\mathrm{R}^{2}$ ) and predicted residual sum of squares (PRESS). The experimental data was fit to four high degree polynomial models viz. linear, interactive (2FI), quadratic and cubic models (Table 3). 
Three different tests, i.e., the sequential model sum of squares, lack of fit tests, and model summary statistics, were applied to predict the adequacy of the models which represent the minimum particle size. The prob $>$ F value of $p<0.0001$, low standard deviation, high $R$-squared, and lower predicted residual error sum of square (PRESS) value suggested to select the quadratic model for the response particle size (Y1). The suggested model for the response encapsulation efficiency (Y2) was the linear model. The model analysis data of the response particle size and encapsulation efficiency are given in Table 4 .

Table 3. Fit summary for the responses particle size $\left(\mathrm{Y}_{1}\right)$ and entrapment efficiency $\left(\mathrm{Y}_{2}\right)$ by $3^{2}$ full factorial design.

\begin{tabular}{|c|c|c|c|c|c|c|c|c|}
\hline \multirow{2}{*}{ Source } & \multicolumn{2}{|c|}{ Sum of Squares } & \multicolumn{2}{|c|}{ df } & \multicolumn{2}{|c|}{ F-Value } & \multicolumn{2}{|c|}{$p$-Value Prob $>\mathrm{F}$} \\
\hline & $Y_{1}$ & $\mathrm{Y}_{2}$ & $\mathrm{Y}_{1}$ & $\mathrm{Y}_{2}$ & $Y_{1}$ & $\mathrm{Y}_{2}$ & $Y_{1}$ & $\mathrm{Y}_{2}$ \\
\hline \multicolumn{9}{|c|}{ Sequential Model Sum of Squares } \\
\hline Mean versus Total & $9.682 \times 10^{5}$ & $26,604.74$ & 1 & 1 & & & & \\
\hline Linear versus Mean & $40,378.14$ & 741.1 & 2 & 2 & 24.96 & 157.99 & 0.0001 & 0.0001 \\
\hline $2 \mathrm{FI} *$ versus Linear & 1998.09 & 0.022 & 1 & 1 & 2.95 & $8.642 \times 10^{-3}$ & 0.1198 & 0.9280 \\
\hline Quadratic versus $2 \mathrm{FI}$ & 4877.38 & 10.71 & 2 & 2 & 14.08 & 2.95 & 0.0035 & 0.1179 \\
\hline Cubic versus Quadratic & 177.92 & 6.63 & 2 & 2 & 0.43 & 2.72 & 0.6725 & 0.1587 \\
\hline Residual & 1034.31 & 6.09 & 5 & 5 & & & & \\
\hline \multicolumn{9}{|c|}{ Lack of Fit Tests } \\
\hline Linear & 7101.59 & 18.78 & 6 & 6 & 4.80 & 2.68 & 0.0754 & 0.1796 \\
\hline $2 \mathrm{FI} *$ & 5103.50 & 18.76 & 5 & 5 & 4.14 & 3.21 & 0.0967 & 0.1406 \\
\hline Quadratic & 226.12 & 8.05 & 3 & 3 & 0.31 & 2.30 & 0.8211 & 0.2194 \\
\hline Cubic & 48.20 & 1.42 & 1 & 1 & 0.20 & 1.22 & 0.6812 & 0.3320 \\
\hline Pure Error & 986.11 & 4.67 & 4 & 4 & & & & \\
\hline \multicolumn{9}{|c|}{ Model Summary Statistics } \\
\hline \multirow[t]{2}{*}{ Source } & \multicolumn{2}{|c|}{$R$-Squared } & \multicolumn{2}{|c|}{$\begin{array}{c}\text { Adjusted } \\
R \text {-Squared }\end{array}$} & \multicolumn{2}{|c|}{ Predicted $R$-Squared } & \multicolumn{2}{|c|}{ PRESS } \\
\hline & Y1 & Y2 & Y1 & Y2 & Y1 & Y2 & Y1 & Y2 \\
\hline Linear & 28.44 & 1.53 & 0.7998 & 0.9632 & 0.6572 & 0.9476 & $16,612.71$ & 40.09 \\
\hline $2 \mathrm{FI} *$ & 26.01 & 1.61 & 0.8325 & 0.9591 & 0.5742 & 0.9166 & $20,636.95$ & 63.73 \\
\hline Quadratic & 13.16 & 1.35 & 0.9571 & 0.9715 & 0.9261 & 0.8901 & 3579.85 & 83.99 \\
\hline Cubic & 14.38 & 1.10 & 0.9488 & 0.9809 & 0.8547 & 0.7752 & 7040.67 & 171.85 \\
\hline
\end{tabular}

$2 \mathrm{FI}^{*}$, sequential sum of squares for the two-factor interaction terms.

Table 4. Analysis of variance of responses of particle size (Y1) and encapsulation efficiency (Y2).

\begin{tabular}{|c|c|c|c|c|c|c|}
\hline Source & Sum of Squares & df & Mean Square & F-Value & $p$-Value Prob $>$ F & - \\
\hline \multicolumn{7}{|c|}{ Response Y1: Particle Size } \\
\hline Model & $47,253.61$ & 5 & 9450.72 & 54.57 & $<0.0001$ & significant \\
\hline A-phase Ratio & $34,367.80$ & 1 & $34,367.80$ & 198.46 & $<0.0001$ & \\
\hline B-sonication Time & 6010.33 & 1 & 6010.33 & 34.71 & 0.0006 & \\
\hline $\mathrm{AB}$ & 1988 & 1 & 1998.09 & 11.54 & 0.0115 & \\
\hline $\mathrm{A}^{2}$ & 3982.76 & 1 & 3982.76 & 23.0 & 0.0020 & \\
\hline $\mathrm{B}^{2}$ & 13.06 & 1 & 13.06 & 0.075 & 0.7916 & \\
\hline Residual & 1212.24 & 7 & 173.18 & & & \\
\hline Lack of Fit & 226.12 & 3 & 75.37 & 0.31 & 0.8211 & not significant \\
\hline Pure Error & 986.11 & 4 & 246.53 & & & \\
\hline Cor Total & $48,465.84$ & 12 & & & & \\
\hline \multicolumn{7}{|c|}{ Response Y2: Encapsulation Efficiency } \\
\hline Model & 741.1 & 2 & 370.55 & 157.99 & $<0.0001$ & significant \\
\hline A-phase Ratio & 655.22 & 1 & 655.22 & 279.36 & $<0.0001$ & \\
\hline B-sonication Time & 85.88 & 1 & 85.88 & 36.62 & 0.0001 & \\
\hline Residual & 23.45 & 10 & 2.35 & & & \\
\hline Lack of Fit & 18.78 & 6 & 3.13 & 2.68 & 0.1796 & not significant \\
\hline Pure Error & 4.67 & 4 & 1.17 & & & \\
\hline Cor Total & 764.55 & 12 & & & & \\
\hline
\end{tabular}


The model F-value of 54.57 for the response $Y_{1}$ and 157.99 for the response $Y_{2}$ translates the significance of the model. Because of the magnitude of the model "F-value", there was only a $0.01 \%$ chance to occur due to the noise. Values of "Prob $>F^{\prime}$ " lower than 0.0500 stand for the significance of the model terms (i.e., $A, B, A B, A^{2}$ ) were significant model terms for the response $Y_{1}$, whereas $A$ and $B$ are significant model terms for the response $Y_{2}$. The model terms were not significant when the values were greater than 0.1000. "Lack of Fit" was not significant with respect to the pure error if the "Lack of Fit F-value" were 0.31 and 2.68 for the responses $Y_{1}$ and $Y_{2}$, respectively. There was an $82.11 \%$ chance for the response $Y_{1}$ and a $17.96 \%$ chance for the response $Y_{2}$ for the "Lack of Fit F-value" of this large to occur due to the noise. The lack of fit was shown not to be significant. The polynomial equation for the measured responses was obtained with the statistical software, generating the following equations for each of the responses:

Particle size $\left(\mathrm{Y}_{1}\right)=254.39-75.68 \mathrm{~A}-31.65 \mathrm{~B}+22.35 \mathrm{AB}+37.97 \mathrm{~A}^{2}+2.17 \mathrm{~B}^{2}$

Encapsulation $\left(\mathrm{Y}_{2}\right)=45.24-10.45 \mathrm{~A}-3.78 \mathrm{~B}$

The equations represent the quantitative effect of variable $(\mathrm{A}, \mathrm{B})$ and their interactions on the responses. Coefficients with more than one factor term and those with higher order terms represent interaction terms and quadratic relationships, respectively. A synergistic effect is represented by a positive trend while an antagonistic effect is represented by a negative trend. The interactions between factors and the responses were further studied by using the contour plot and the 3D response surface plot (Figure 3). It is evident from the plot that both particle size and encapsulation efficiency decreased as the aqueous-to-oil phase ratio increased. Similarly, an increase in the sonication time also led to a decrease in the particle size, as well as the encapsulation efficiency, but the effect was slightly lower when compared to the phase ratio.
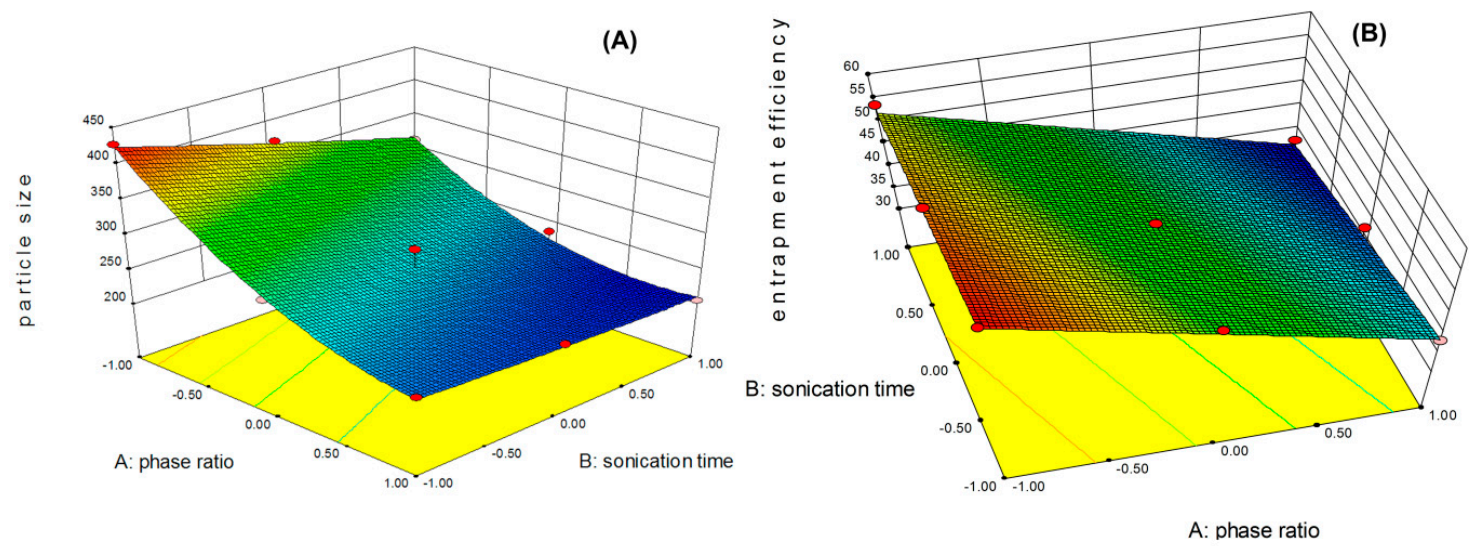

Figure 3. The 3D response surface plot of the responses for particle size $\mathrm{Y} 1$ (A) and encapsulation efficiency $\mathrm{Y} 2$ (B).

Based on the results obtained from the DoE, the formulations selected for the preparation of drug-loaded nanoparticles are given in Table 5.

Table 5. Composition of the optimized formulation of DCT-loaded T $f$-conjugated PLGA NPs and predicted and actual responses.

\begin{tabular}{cccccc}
\hline Factors & Level & \multicolumn{2}{c}{ Average Particle Size $(\mathbf{n m})$} & \multicolumn{2}{c}{ Average Encapsulation Efficiency (\%) } \\
\hline Phase ratio & $1: 4.7$ & Predicted & Real & Predicted & Real \\
\hline Sonication time $(\mathrm{min})$ & 10 & 206.2 & $210.6 \pm 2.7$ & 34.1 & $36.1 \pm 2.3$ \\
\hline
\end{tabular}

The above levels of factors (Table 5) were used for the production of an optimized formulation. The amount of dodecyl trihydrate added to the formulation was $5 \mathrm{mg}$, the amount of polymer was fixed to $10 \mathrm{mg}$, PVA concentration was $2 \%$, and sonication amplitude used was $40 \mathrm{~W}$. The DCT-loaded 
$\mathrm{T} f$-conjugated PLGA NPs depicted a mean particle size of $210.6 \pm 2.7 \mathrm{~nm}$ (polydispersity index (PDI) of $0.131 \pm 0.021$ ), while DCT-loaded PLGA NPs showed a mean size of $183 \pm 2.4 \mathrm{~nm}$ and PDI of $0.027 \pm 0.003$.

The FTIR spectrum of the drug-loaded nanoparticles were compared to that of the physical mixture of docetaxel trihydrate and polymer (Supplementary Materials Figure S1). All the characteristic peaks of docetaxel trihydrate and PLGA-EDA-transferrin conjugate were present in the IR spectrum of the nanoparticles. An additional small peak at $1709 \mathrm{~cm}^{-1}$ was also recorded and was attributed to the formation of an amide bond between PLGA with EDA and EDA with transferrin during the conjugation process.

The prepared nanoparticles were analyzed by DSC in order to understand the physical status, in comparison to the bulk counterparts (Supplementary Materials Figure S2). The thermal analysis was considered as a tool for examining whether the solute particles were dispersed well in the polymeric matrices. The DSC thermogram of docetaxel-loaded nanoparticles exhibited endothermic peaks at $48^{\circ} \mathrm{C}$ and $93^{\circ} \mathrm{C}$, attributed to the presence of PLGA and transferrin, respectively. The endothermic peak in the range of $165^{\circ} \mathrm{C}$ to $175^{\circ} \mathrm{C}$, which was previously observed in the independent thermogram of DCT and its physical mixture, was not observed in the nanoparticles. The absence of the DCT peak in the nanoparticle formulation confirms that drug molecules were dispersed in the polymeric network to form a homogenous matrix.

To study the interaction between drug and polymer and the degree of sample crystallinity, the results of the PXRD analysis of DCT-loaded T $f$-conjugated PLGA NPs were compared to those obtained for the physical mixture of drug and polymers. The characteristic peaks of DCT at $2 \theta$ angles of 10.3, $11.1,14.2,17.8,19.8$, and $22.2^{\circ}$ were present in the physical mixture, which indicates the crystalline nature of the drug DCT (Supplementary Materials Figure S3A and S3B). The DCT-loaded T $f$-conjugated PLGA NPs showed no sharp peaks in the DSC thermogram (Supplementary Materials Figure S3C). This translates the amorphous and disordered-crystalline phase of the drug within the polymeric matrix of the NPs or its presence in the form of molecular dispersion.

The shape and surface morphology were analyzed by TEM. Surface morphology analysis showed PLGA nanoparticles of homogenous, smooth, and spherical shape, discrete, and of a uniform size distribution (Figure 4), while freeze-drying did not cause much nanoparticle aggregation (data not shown). Figure 4 depicts some droplets of organic solvent (DMSO) which corresponded to the inner phase used in the production of the nanoparticles by the solvent evaporation technique. This was attributed to the incomplete evaporation of DMSO, after which PLGA NPs should depict a dense, continuous polymeric network (as exhibited by the darker NPs). Important to note is the absence of drug recrystallized in the aqueous phase while the spherical shape of NPs ensures minimum segregation effect.

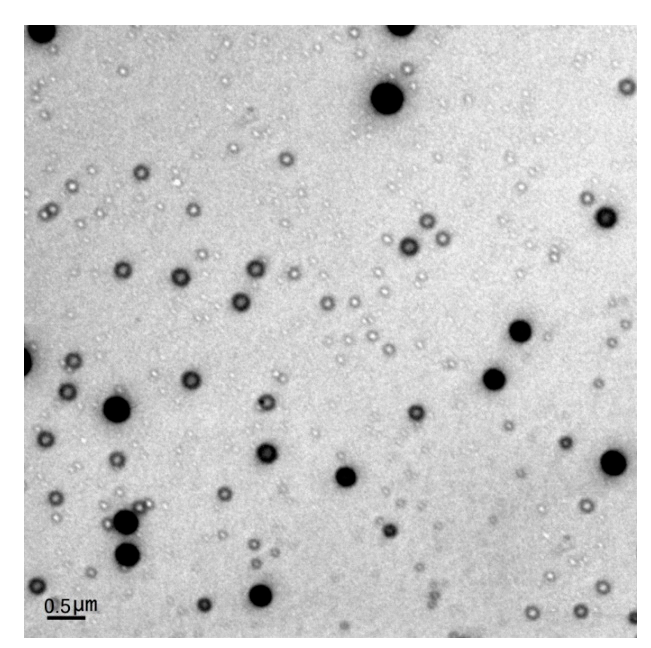

Figure 4. TEM image of DCT-loaded Tf-conjugated PLGA NPs. 
The optimized nanoparticles were evaluated for particle size and zeta potential, and the results are shown in Supplementary Materials Figure S4A and S4B. The mean particle size was found to be $210.6 \pm 2.7 \mathrm{~nm}$ and the zeta potential approximately $-24.5 \mathrm{mV}$. While the literature recommends a minimum zeta potential of $\pm 40 \mathrm{mV}$ for nanosuspensions to show stability solely by electrostatic repulsion, according to the DLVO theory, the obtained zeta potential values for the produced nanoparticles contributed for their physical stability on the shelf-life.

The in vitro release profiles of DCT-loaded $\mathrm{T} f$-conjugated PLGA NPs were obtained by suspending the prepared nanoparticles in phosphate buffer $\mathrm{pH} 7.4$ and quantifying the DCT solubilized in the medium. The release of DCT from $\mathrm{T} f$-conjugated PLGA NPs for a period of $48 \mathrm{~h}$ was determined using the HPLC method [49]. The cumulative percentage release data of DCT was plotted against time, and it was compared to the unconjugated DCT-loaded nanoparticles (Figure 5). The cumulative percentage of drug release of Tf-conjugated PLGA NPs $(90.31 \% \pm 2.98 \%)$ was found to be lower than unconjugated NPs $(96.42 \% \pm 3.24 \%)$ at the end of $48 \mathrm{~h}$. This result was attributed to the increase in the structural complexity of the polymer due to the transferrin conjugation.

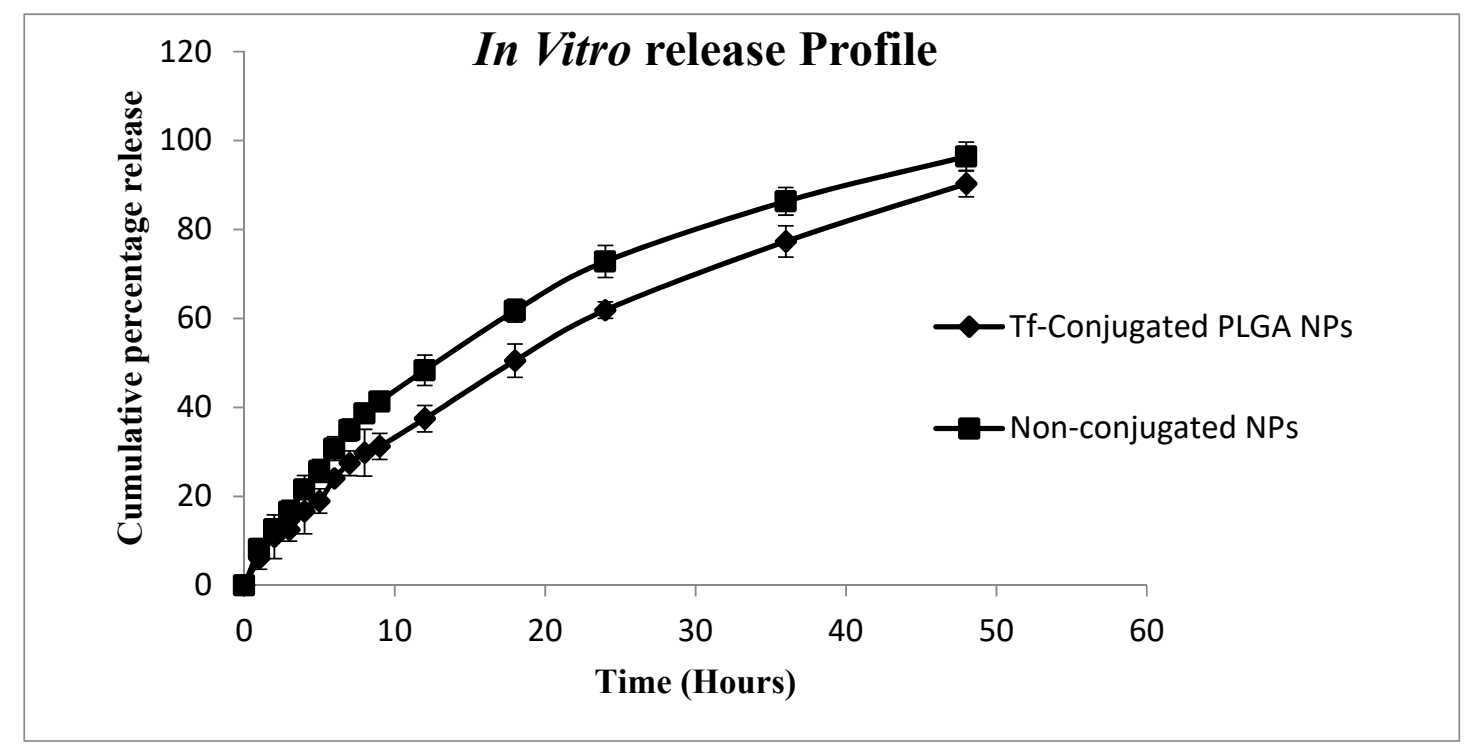

Figure 5. In vitro release profile of DCT-loaded $\mathrm{T} f$-conjugated PLGA NPs and unconjugated nanoparticles.

The modified release profile of both $\mathrm{T} f$-conjugated PLGA NPs and non-conjugated NPs anticipate that the drug was indeed within the polymeric matrix which modulates its release. These results corroborate those obtained from the ${ }^{1} \mathrm{HNMR}$. The DCT was released from $\mathrm{T} f$-conjugated PLGA NPs in a sustained fashion over a period of $48 \mathrm{~h}$.

Kinetic analysis of the release profile was carried out to determine the exact mechanism of the drug release (Figure 6). The adjustment of the release date for the different mathematical models helped us to describe if the release depended on the drug concentration within the particles (first-order kinetics), whether it was independent on the drug concentration being therefore predictable and at a constant rate (zero-order kinetics) or if it followed a Fickian diffusion. The Higuchi release model describes the release of drugs from an insoluble matrix as a square root of a time-dependent process based on Fickian diffusion and is commonly seen in nanoparticles. In the Korsmeyer-Peppas, for spherical monodispersed particles, a value $\mathrm{n}-0.43$ is characteristic for Fickian diffusion, but for polydisperse particles to follow Fickian diffusion they should show a lower $n$ value of 0.30 , for example [50]. Fickian diffusion stands for the classical diffusion that is controlled by a gradient or differences of concentrations. The zero-order correlation co-efficient value of 0.9556 indicates that the release profile of DCT from T $f$-conjugated PLGA NPs fitted into zero-order kinetics, better than into first-order 
kinetics. The drug release was diffusion controlled as indicated by the higher $R^{2}$ value (0.9865) in the Higuchi model. Since the $n$ value (0.7066) obtained from the Korsmeyer-Peppas model or the optimized formulation was between 0.45 and 0.89 , the mechanism of drug release from the PLGA NPs was found to follow a non-Fickian diffusion.
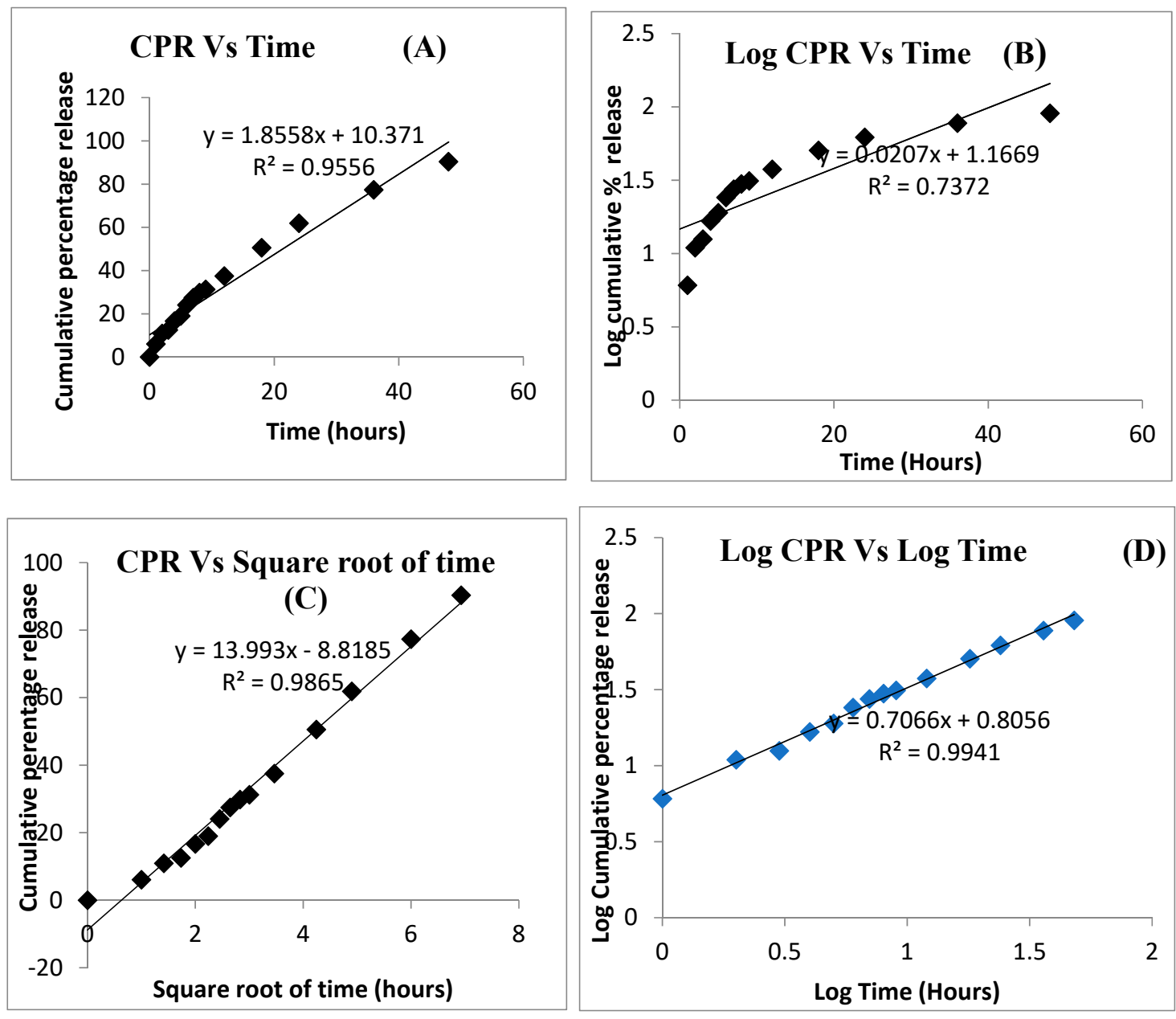

Figure 6. Kinetic assessment of drug release from $\mathrm{T} f$-conjugated PLGA NPs using various kinetic models: (A) zero-order kinetics, (B) first-order kinetics, (C) Higuchi's model, and (D) Korsmeyer-Peppa's model.

The in vitro cytotoxicity of MCF-7 cells incubated with various DCT-loaded Tf-conjugated PLGA NPs at different drug concentrations was studied by the MTT method. Based on the results shown in Table 6, the various nanoparticle formulations exhibited a dose-dependent cytotoxicity against MCF-7 cells. The cytotoxic potential of DCT-loaded T $f$-conjugated PLGA NPs were much higher than the pure drug, as seen from the $\mathrm{IC}_{50}$ values. $\mathrm{An} \mathrm{IC}_{50}$ value of $7.1 \mu \mathrm{M} / \mathrm{mL}$ was recorded for the pure docetaxel trihydrate. When loaded into nanoparticles, the $\mathrm{IC}_{50}$ was $4.392 \mu \mathrm{M} / \mathrm{mL}$ (DCT-loaded Tf-conjugated PLGA NPs), which was significantly lower than the $\mathrm{IC}_{50}$ of unconjugated nanoparticles $(6.24 \mu \mathrm{M} / \mathrm{mL}$, DCT-loaded PLGA NPs). In other words, the conjugation of transferrin improved the efficiency of the chemotherapeutic formulation in comparison to the non-conjugated counterpart. These results also corroborate the conclusion that the drug is indeed entrapped within the PLGA matrix. 
Table 6. In vitro cytotoxicity assay in MCF-7 cell lines.

\begin{tabular}{|c|c|c|c|c|}
\hline Compound Name & Concentration $(\mu \mathrm{M} / \mathrm{mL})$ & Mean Cell Death & SEM & $\mathrm{IC}_{50}(\mu \mathrm{M} / \mathrm{mL})$ \\
\hline \multirow{4}{*}{ Docetaxel } & 0.25 & 16.5 & 2.9 & \multirow{4}{*}{7.097} \\
\hline & 0.5 & 23.0 & 1.1 & \\
\hline & 1 & 41.6 & 1.0 & \\
\hline & 2 & 51.0 & 0.7 & \\
\hline \multirow{4}{*}{$\begin{array}{l}\text { DCT-loaded } \\
\text { PLGA NPs }\end{array}$} & 0.25 & 25.5 & 0.9 & \multirow{4}{*}{6.24} \\
\hline & 0.5 & 36.4 & 3.6 & \\
\hline & 1 & 43.8 & 0.6 & \\
\hline & 2 & 53.0 & 1.0 & \\
\hline \multirow{4}{*}{$\begin{array}{l}\text { DCT-loaded } \\
\text { T } f \text {-conjugated } \\
\text { PLGA NPs }\end{array}$} & 0.25 & 23.0 & 1.1 & \multirow{4}{*}{4.392} \\
\hline & 0.5 & 41.6 & 1.0 & \\
\hline & 1 & 51.0 & 0.7 & \\
\hline & 2 & 56.6 & 0.8 & \\
\hline \multirow{4}{*}{ Blank NPs } & 100 & 18.2 & 7.2 & \multirow{4}{*}{$800 \mu \mathrm{g} / \mathrm{mL}$} \\
\hline & 200 & 16.0 & 4.0 & \\
\hline & 400 & 19.3 & 3.9 & \\
\hline & 800 & 15.8 & 10.4 & \\
\hline
\end{tabular}

The cell viability of blank nanoparticles was simultaneously examined, and it was found to be between $80 \%$ and $90 \%$. This result indicates that blank NPs did not cause evident cytotoxicity. Targeted NPs are taken up by cells via receptor-mediated endocytosis and are not subjected to efflux by P-glycoprotein. The result is a higher cytotoxic effect because the chemotherapeutic compound is efficiently released inside tumor cells. The ANOVA results confirmed that there is a significantly higher cytotoxic effect for transferrin-conjugated nanoparticles than the unconjugated nanoparticles. This result was attributed to the increased targeting potential of the drug-loaded NPs resulting from the ligand binding on the transferrin receptor of the MCF-7 cell line.

To evaluate the targeting ability of the nanoparticles, the cellular uptake of coumarin-6-loaded PLGA and PLGA-EDA-Tr nanoparticles by MCF-7 cells was investigated (Figure 7). After an incubation period of $2 \mathrm{~h}$ and $24 \mathrm{~h}$, the mean fluorescence was recorded and analyzed. Cells without coumarin were used as a control to show the auto-fluorescence. There was an increase in the fluorescence intensity in a time-dependent fashion with the conjugated nanoparticles compared to the unconjugated nanoparticles. This result was attributed to the presence of transferrin moiety on the outside surface of the nanoparticles enabling their binding with transferrin receptors on the tumor cells and subsequent receptor mediated endocytosis.

The quantitative results for the mean fluorescence of MCF-7 cells $2 \mathrm{~h}$ and $24 \mathrm{~h}$ after treatment with DCT-loaded T $f$-conjugated PLGA NPs are summarized in Table 7.

The cell cycle analysis of MCF-7 cells was carried out after incubating DCT-loaded Tf-conjugated PLGA NPs at their respective $\mathrm{IC}_{50}$ concentrations. Four distinct phases could be recognized in a proliferating cell population, namely, the G1-, S- (DNA synthesis phase), G2-, and M-phase (mitosis). However, G2- and M-phase, both having an identical DNA content, could not be discriminated based on their differences in DNA content.

The control MCF-7 cells showed a cell cycle pattern with $68.5 \%$ cells in G0/G1 phase, $15.9 \%$ in S phase, and $16.0 \%$ cells in G2/M phase (Figure $8 \mathrm{~A}$ ). The blank nanoparticles (Figure $8 \mathrm{~B}$ ) did not show any significant effect on the cell cycle. The pure drug docetaxel trihydrate (Figure $8 \mathrm{C}$ ) arrested the cell cycle in G2/M phase. The targeted nanoparticles were also able to arrest the cells at G2/M phase with a cell cycle pattern of $32.8 \%$ cells in G0/G1 phase, $7.6 \%$ in S phase, and $59.6 \%$ cells in G2/M phase (Figure 8E). 

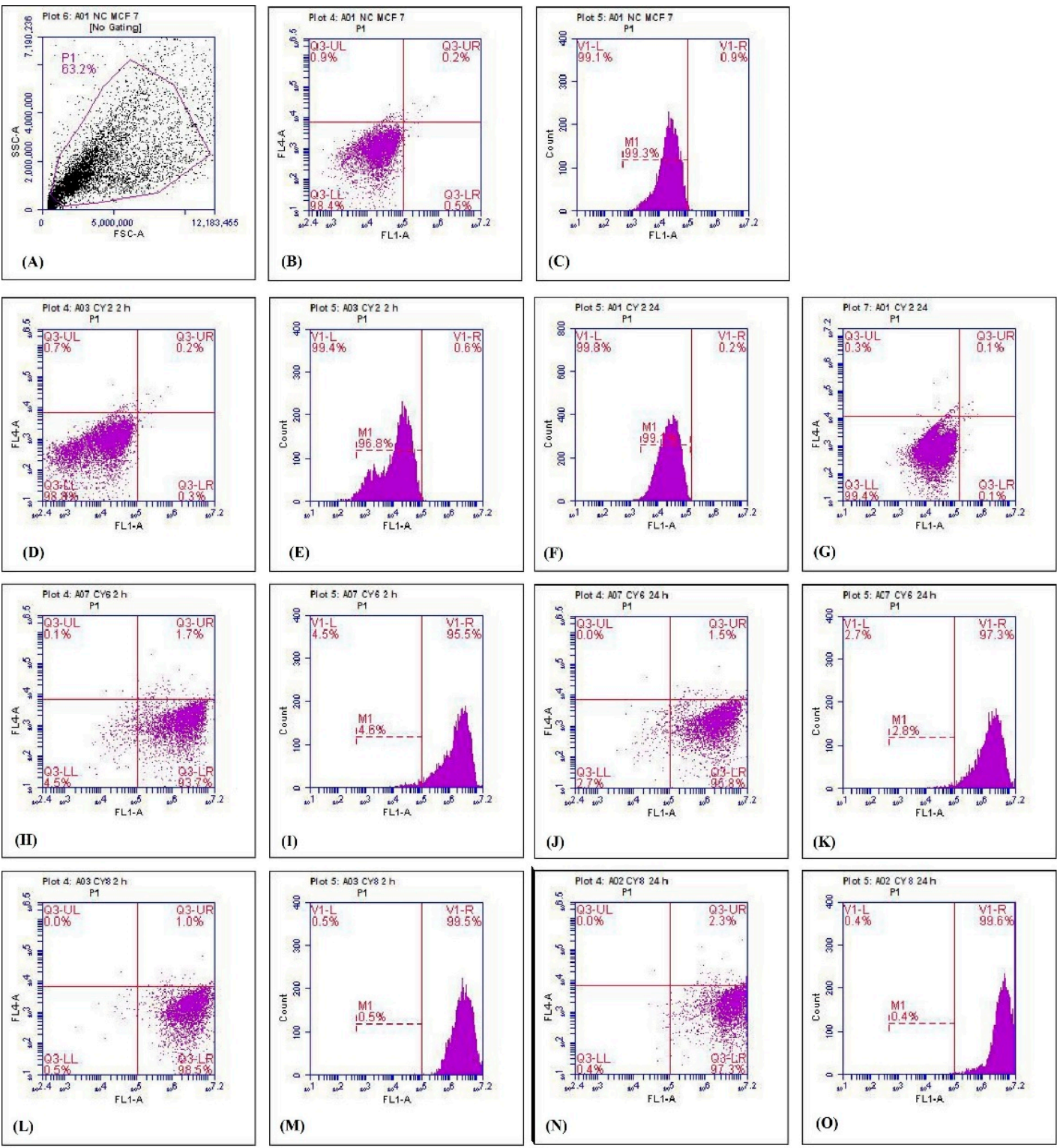

Figure 7. Cellular uptake study using flow cytometry: (A) gating, (B,C) fluorescence of untreated MCF-7 cells, (D,E) fluorescence of blank nanoparticles at $2 \mathrm{~h},(\mathbf{F}, \mathrm{G})$ fluorescence of blank nanoparticles at $24 \mathrm{~h},(\mathbf{H}, \mathbf{I})$ fluorescence of unconjugated nanoparticles at $2 \mathrm{~h},(\mathbf{J}, \mathbf{K})$ fluorescence of unconjugated na-noparticles at $24 \mathrm{~h},(\mathbf{L}, \mathbf{M})$ fluorescence of DCT-loaded T $f$-conjugated PLGA NPs at $2 \mathrm{~h},(\mathbf{N}, \mathbf{O})$ flu-orescence of $\mathrm{T} f$-conjugated PLGA NP at $24 \mathrm{~h}$. The $x$ - and $y$-axes correspond to forward scatter (FSC) (which measures size) and side scatter (SSC) (which measures internal complexity), respectively. The FL1-area stands for total cell fluorescence.

Table 7. Mean fluorescence analysis of MCF-7 cells $2 \mathrm{~h}$ and $24 \mathrm{~h}$ after treatment with blank NPs, DCT-loaded PLGA NPs, and DCT-loaded T $f$-conjugated PLGA NPs.

\begin{tabular}{ccc}
\hline \multirow{2}{*}{ Samples } & \multicolumn{2}{c}{ Mean Fluorescence } \\
\cline { 2 - 3 } & $\mathbf{2} \mathbf{~ h}$ & $\mathbf{2 4} \mathbf{~ h}$ \\
\hline Blank NPs & $27,294.1$ & $32,914.2$ \\
DCT-loaded PLGA NPs & $2,930,523.01$ & $3,085,163.04$ \\
DCT-loaded Tf-conjugated PLGA NPs & $4,153,708.4$ & $7,550,576.4$ \\
\hline
\end{tabular}



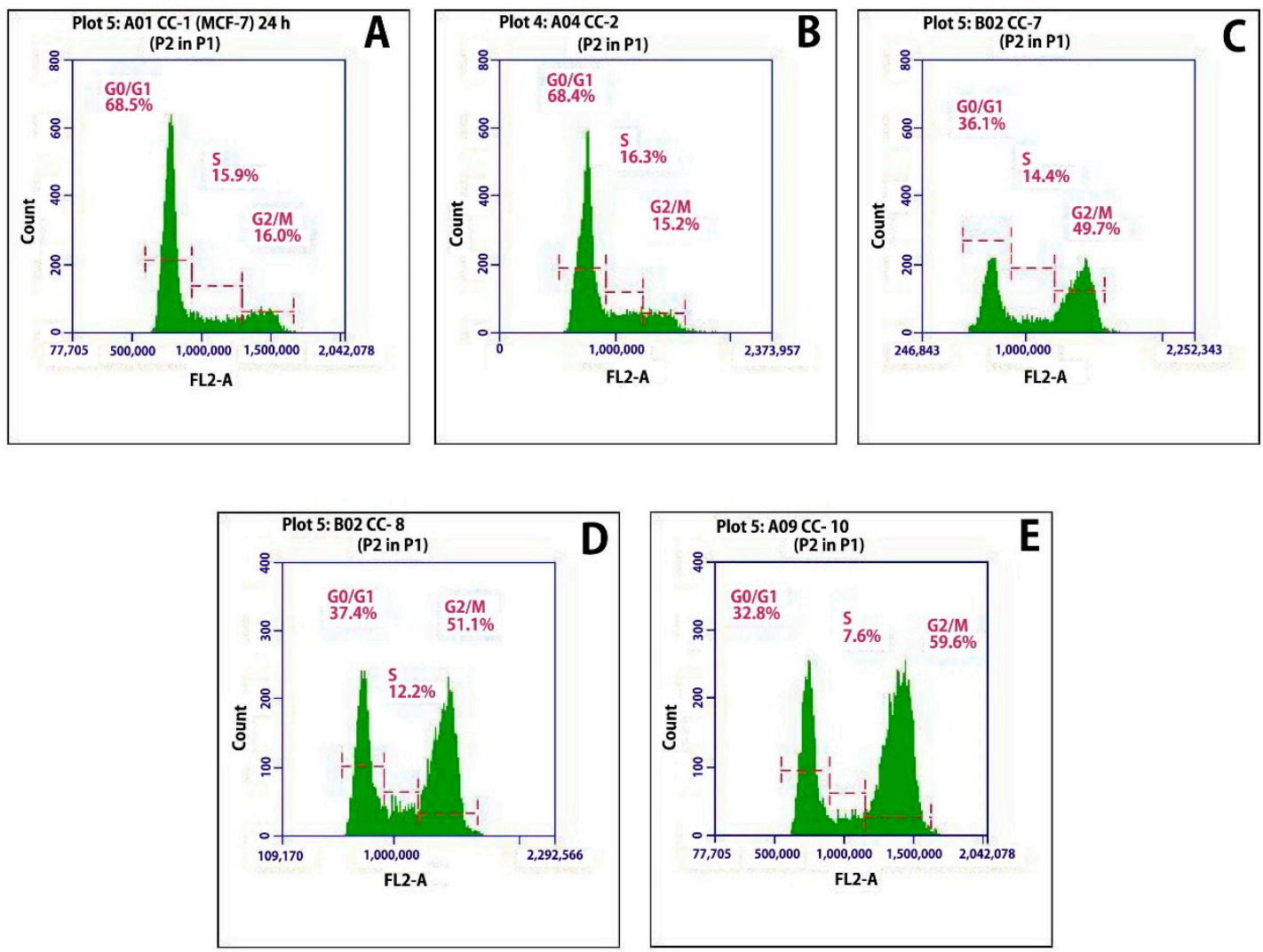

Figure 8. Effect on cell cycle of MCF-7 cells after $24 \mathrm{~h}$ of treatment. Control MCF-7 cells (A), blank nanoparticles (B), docetaxel trihydrate (C), non-conjugated nanoparticles (D), and DCT-loaded Tf-conjugated PLGA NPs (E). The FL2-area stands for total cell fluorescence.

\section{Conclusions}

Active targeting of the drug molecules with the help of a ligand-conjugated nanoparticles could reduce the undesirable side effects of tumor therapy. In our study, we successfully synthesized PLGA-transferrin conjugate using a novel technique with EDA as a linker. The drug-loaded PLGA nanoparticles were effectively optimized by $3^{2}$ full factorial design. The FTIR, DSC, PXRD, TEM, particle size, and zeta potential analyses were carried out to characterize the developed nanoparticles. FTIR, DSC, and PXRD analysis confirmed the successful development of ligand-conjugated nanoparticles. The TEM images revealed the particle size and spherical shape of the developed nanoparticles which will limit the systemic distribution of the chemotherapeutic drug in vivo. Particle size distribution by DLS technique showed that the transferrin-conjugated NPs were within an acceptable range. The zeta potentials of the formulations were between -32 and $-24 \mathrm{mV}$, which indicates good colloidal stability due to the repulsive forces. The in vitro release kinetics revealed that the drug release followed a zero-order kinetics by a non-Fickian diffusion mechanism. The effectiveness of developed conjugated NPs was evaluated in vitro against MCF-7 cells. Cytotoxicity studies confirmed that ligand-conjugated NPs are more effective than unconjugated NPs. Cell uptake studies re-confirmed the ligand-mediated active targeting of the formulated NPs. Cell cycle analysis concluded that the anti-cancer activity of all the developed formulation is by arresting the $\mathrm{G}_{2} / \mathrm{M}$ phase in accordance with the literature of docetaxel trihydrate.

Supplementary Materials: The following are available online at http://www.mdpi.com/2073-4360/11/11/1905/s1, Figure S1. FTIR spectrum of docetaxel trihydrate (DCT) (upper), of physical mixture of docetaxel trihydrate, transferrin (Tf) and PLGA (middle), and of DCT-loaded T $f$-conjugated PLGA NPs (lower); Figure S2. DSC thermogram of PLGA (A), transferrin (B), docetaxel trihydrate (C), their physical mixture (D) and of DCT-loaded $\mathrm{T} f$-conjugated PLGA NPs (E); Figure S3. (A) X-ray diffraction pattern of docetaxel trihydrate, (B) physical mixture of docetaxel trihydrate, transferrin and PLGA, and of (C) DCT-loaded Tf-conjugated PLGA NPs. Figure S4. 
(A) Particle size distribution and average particle size and (B) zeta potential of DCT-loaded Tf-conjugated PLGA NPs.

Author Contributions: Conceptualization, methodology, validation, investigation, analysis, data curation, and revision were performed by S.J., T.A.C., R.S., M.H.S., N.A.A. and E.B.S. Writing, review, editing, and resourcing by S.J., A.D., M.L., A.S., and E.B.S. All authors substantially contributed to the work.

Funding: The authors would like to acknowledge the financial support of All India Council for Technical Education (AICTE), New Delhi, India, under Research Promotion Scheme (RPS 2012-2013). The authors are also thankful to the Portuguese Foundation for Science and Technology (FCT/MEC) for funding the project M-ERA-NET-0004/2015 (PAIRED), through national funds and co-financed by FEDER under the Partnership Agreement PT2020. The authors acknowledge the support of the research project: Nutraceutica come supporto nutrizionale nel paziente oncologico, CUP: B83D18000140007.

Acknowledgments: The authors wish to thank Mac Chem Products Pvt Ltd. (Mumbai, India) for the kind gift of docetaxel trihydrate.

Conflicts of Interest: The authors declare no conflict of interest.

\section{References}

1. Chen, J.J.; Liu, S.P.; Zhao, J.; Wang, S.C.; Liu, T.J.; Li, X. Effects of a novel photoactivated photosensitizer on MDR1 over-expressing human breast cancer cells. J. Photochem. Photobiol. B Biol. 2017, 171, 67-74. [CrossRef]

2. Fathi, M.; Barar, J. Perspective highlights on biodegradable polymeric nanosystems for targeted therapy of solid tumors. Bioimpacts 2017, 7, 49-57. [CrossRef] [PubMed]

3. Milling, L.; Zhang, Y.; Irvine, D.J. Delivering safer immunotherapies for cancer. Adv. Drug Deliv. Rev. 2017. [CrossRef] [PubMed]

4. Cano, A.; Ettcheto, M.; Chang, J.H.; Barroso, E.; Espina, M.; Kuhne, B.A.; Barenys, M.; Auladell, C.; Folch, J.; Souto, E.B.; et al. Dual-drug loaded nanoparticles of Epigallocatechin-3-gallate (EGCG)/Ascorbic acid enhance therapeutic efficacy of EGCG in a APPswe/PS1dE9 Alzheimer's disease mice model. J. Control. Release Off. J. Control. Release Soc. 2019, 301, 62-75. [CrossRef] [PubMed]

5. Sanchez-Lopez, E.; Egea, M.A.; Cano, A.; Espina, M.; Calpena, A.C.; Ettcheto, M.; Camins, A.; Souto, E.B.; Silva, A.M.; Garcia, M.L. PEGylated PLGA nanospheres optimized by design of experiments for ocular administration of dexibuprofen-in vitro, ex vivo and in vivo characterization. Colloids Surf. B Biointerfaces 2016, 145, 241-250. [CrossRef]

6. Sanchez-Lopez, E.; Ettcheto, M.; Egea, M.A.; Espina, M.; Cano, A.; Calpena, A.C.; Camins, A.; Carmona, N.; Silva, A.M.; Souto, E.B.; et al. Memantine loaded PLGA PEGylated nanoparticles for Alzheimer's disease: In vitro and in vivo characterization. J. Nanobiotechnol. 2018, 16, 32. [CrossRef]

7. Cocco, E.; Deng, Y.; Shapiro, E.M.; Bortolomai, I.; Lopez, S.; Lin, K.; Bellone, S.; Cui, J.; Menderes, G.; Black, J.D.; et al. Dual-Targeting Nanoparticles for In Vivo Delivery of Suicide Genes to Chemotherapy-Resistant Ovarian Cancer Cells. Mol. Cancer Ther. 2017, 16, 323-333. [CrossRef]

8. Harguindey, A.; Domaille, D.W.; Fairbanks, B.D.; Wagner, J.; Bowman, C.N.; Cha, J.N. Synthesis and Assembly of Click-Nucleic-Acid-Containing PEG-PLGA Nanoparticles for DNA Delivery. Adv. Mater. 2017. [CrossRef]

9. Matsumura, Y.; Maeda, H. A new concept for macromolecular therapeutics in cancer chemotherapy: Mechanism of tumoritropic accumulation of proteins and the antitumor agent smancs. Cancer Res. 1986, 46, 6387-6392.

10. Li, N.; Yang, X.; Zhai, G.; Li, L. Multifunctional pluronic/poly(ethylenimine) nanoparticles for anticancer drug. J. Colloid Interface Sci. 2010, 350, 117-125. [CrossRef]

11. Patil, Y.; Sadhukha, T.; Ma, L.; Panyam, J. Nanoparticle-mediated simultaneous and targeted delivery of paclitaxel and tariquidar overcomes tumor drug resistance. J. Control. Release Off. J. Control. Release Soc. 2009, 136, 21-29. [CrossRef] [PubMed]

12. El-Hammadi, M.M.; Delgado, A.V.; Melguizo, C.; Prados, J.C.; Arias, J.L. Folic acid-decorated and PEGylated PLGA nanoparticles for improving the antitumour activity of 5-fluorouracil. Int. J. Pharm. 2017, 516, 61-70. [CrossRef] [PubMed]

13. Liang, H.; He, L.; Zhou, B.; Li, B.; Li, J. Folate-functionalized assembly of low density lipoprotein/sodium carboxymethyl cellulose nanoparticles for targeted delivery. Colloids Surf. B Biointerfaces 2017, 156, 19-28. [CrossRef] [PubMed] 
14. Liang, X.; Fan, J.; Zhao, Y.; Cheng, M.; Wang, X.; Jin, R.; Sun, T. A targeted drug delivery system based on folic acid-functionalized upconversion luminescent nanoparticles. J. Biomater. Appl. 2017, 31, 1247-1256. [CrossRef] [PubMed]

15. Xu, L.; Bai, Q.; Zhang, X.; Yang, H. Folate-mediated chemotherapy and diagnostics: An updated review and outlook. J. Control. Release Off. J. Control. Release Soc. 2017, 252, 73-82. [CrossRef] [PubMed]

16. Cui, Y.N.; Xu, Q.X.; Davoodi, P.; Wang, D.P.; Wang, C.H. Enhanced intracellular delivery and controlled drug release of magnetic PLGA nanoparticles modified with transferrin. Acta Pharmacol. Sin. 2017, 38, 943-953. [CrossRef] [PubMed]

17. Ruttala, H.B.; Ramasamy, T.; Poudal, B.K.; Choi, Y.; Choi, J.Y.; Kim, J.; Kwang Ku, S.; Choi, H.G.; Soon Yong, C.; Oh Kim, J. Molecularly targeted co-delivery of a histone deacetylase inhibitor and paclitaxel by lipid-protein hybrid nanoparticles for synergistic combinational chemotherapy. Oncotarget 2017, 8, 14925-14940. [CrossRef]

18. Liu, Y.; Hui, Y.; Ran, R.; Yang, G.-Z.; Wibowo, D.; Wang, H.-F.; Middelberg, A.P.J.; Zhao, C.-X. Synergetic Combinations of Dual-Targeting Ligands for Enhanced In Vitro and In Vivo Tumor Targeting. Adv. Healthc. Mater. 2018, 7, 1800106. [CrossRef]

19. Venditto, V.J.; Szoka, F.C., Jr. Cancer nanomedicines: So many papers and so few drugs! Adv. Drug Deliv. Rev. 2013, 65, 80-88. [CrossRef]

20. Menditto, E.; Guerriero, F.; Orlando, V.; Crola, C.; Di Somma, C.; Illario, M.; Morisky, D.E.; Colao, A. Self-Assessment of Adherence to Medication: A Case Study in Campania Region Community-Dwelling Population. J. Aging Res. 2015, 2015, 682503. [CrossRef]

21. Putignano, D.; Bruzzese, D.; Orlando, V.; Fiorentino, D.; Tettamanti, A.; Menditto, E. Differences in drug use between men and women: An Italian cross sectional study. BMC Womens Health 2017, 17, 73. [CrossRef] [PubMed]

22. Menditto, E.; Cahir, C.; Aza-Pascual-Salcedo, M.; Bruzzese, D.; Poblador-Plou, B.; Malo, S.; Costa, E.; González-Rubio, F.; Gimeno-Miguel, A.; Orlando, V.; et al. Adherence to chronic medication in older populations: Application of a common protocol among three European cohorts. Patient Prefer. Adher. 2018, 12, 1975-1987. [CrossRef] [PubMed]

23. Scala, D.; Menditto, E.; Armellino, M.F.; Manguso, F.; Monetti, V.M.; Orlando, V.; Antonino, A.; Makoul, G.; De Palma, M. Italian translation and cultural adaptation of the communication assessment tool in an outpatient surgical clinic. BMC Health Serv. Res. 2016, 16, 163. [CrossRef] [PubMed]

24. Souto, E.B.; Dias-Ferreira, J.; Lopez-Machado, A.; Ettcheto, M.; Cano, A.; Camins Espuny, A.; Espina, M.; Garcia, M.L.; Sanchez-Lopez, E. Advanced Formulation Approaches for Ocular Drug Delivery: State-Of-The-Art and Recent Patents. Pharmaceutics 2019, 11, 460. [CrossRef] [PubMed]

25. Abrego, G.; Alvarado, H.; Souto, E.B.; Guevara, B.; Bellowa, L.H.; Garduno, M.L.; Garcia, M.L.; Calpena, A.C. Biopharmaceutical profile of hydrogels containing pranoprofen-loaded PLGA nanoparticles for skin administration: In vitro, ex vivo and in vivo characterization. Int. J. Pharm. 2016, 501, 350-361. [CrossRef]

26. Abrego, G.; Alvarado, H.; Souto, E.B.; Guevara, B.; Bellowa, L.H.; Parra, A.; Calpena, A.; Garcia, M.L. Biopharmaceutical profile of pranoprofen-loaded PLGA nanoparticles containing hydrogels for ocular administration. Eur. J. Pharm. Biopharm. 2015, 95, 261-270. [CrossRef]

27. Araujo, J.; Vega, E.; Lopes, C.; Egea, M.A.; Garcia, M.L.; Souto, E.B. Effect of polymer viscosity on physicochemical properties and ocular tolerance of FB-loaded PLGA nanospheres. Colloids Surf. B Biointerfaces 2009, 72, 48-56. [CrossRef]

28. Canadas, C.; Alvarado, H.; Calpena, A.C.; Silva, A.M.; Souto, E.B.; Garcia, M.L.; Abrego, G. In vitro, ex vivo and in vivo characterization of PLGA nanoparticles loading pranoprofen for ocular administration. Int. J. Pharm. 2016, 511, 719-727. [CrossRef]

29. Jose, S.; Sowmya, S.; Cinu, T.A.; Aleykutty, N.A.; Thomas, S.; Souto, E.B. Surface modified PLGA nanoparticles for brain targeting of Bacoside-A. Eur. J. Pharm. Sci. Off. J. Eur. Fed. Pharm. Sci. 2014, 63, 29-35. [CrossRef]

30. Sanchez-Lopez, E.; Egea, M.A.; Davis, B.M.; Guo, L.; Espina, M.; Silva, A.M.; Calpena, A.C.; Souto, E.M.B.; Ravindran, N.; Ettcheto, M.; et al. Memantine-Loaded PEGylated Biodegradable Nanoparticles for the Treatment of Glaucoma. Small 2018, 14. [CrossRef]

31. Wani, M.C.; Taylor, H.L.; Wall, M.E.; Coggon, P.; McPhail, A.T. Plant antitumor agents. VI. The isolation and structure of taxol, a novel antileukemic and antitumor agent from Taxus brevifolia. J. Am. Chem. Soc. 1971, 93, 2325-2327. [CrossRef] [PubMed] 
32. Dong, X.; Wang, L.; Han, Z.; Zhou, L.; Shan, L.; Ding, Y.; Xu, W.; Li, J.; Su, Y.; Cai, R.; et al. Different functions of DEPTOR in modulating sensitivity to chemotherapy for esophageal squamous cell carcinoma. Exp. Cell Res. 2017, 353, 35-45. [CrossRef] [PubMed]

33. Fernandez, E.; Cacheux, W.; Frossard, J.L.; Koessler, T.; Abou, M.; Moniez, M.; Huber, O.; Puppa, G.; Roth, A. Exclusive neoadjuvant chemotherapy in locally advanced resectable gastric and gastro-esophageal junction adenocarcinoma. Dig. Liver Dis. Off. J. Ital. Soc. Gastroenterol. Ital. Assoc. Study Liver 2017, 49, 552-556. [CrossRef] [PubMed]

34. Pfeiffer, P.; Qvortrup, C.; Krogh, M.; Schoennemann, K.; Vestermark, L.W.; Jensen, H.A.; Bjerregaard, J.K. S-1 in combination with docetaxel and oxaliplatin in patients with advanced gastro-esophageal adenocarcinoma: Two parallel phase 1/2a studies. Acta Oncol. 2017, 56, 46-51. [CrossRef] [PubMed]

35. Su, X.; Gao, C.; Shi, F.; Feng, X.; Liu, L.; Qu, D.; Wang, C. A microemulsion co-loaded with Schizandrin A-docetaxel enhances esophageal carcinoma treatment through overcoming multidrug resistance. Drug Deliv. 2017, 24, 10-19. [CrossRef] [PubMed]

36. Yamashita, K.; Hosoda, K.; Moriya, H.; Katada, C.; Sugawara, M.; Mieno, H.; Komori, S.; Katada, N.; Watanabe, M. Prognostic Advantage of Docetaxel/Cisplatin/5-Fluorouracil Neoadjuvant Chemotherapy in Clinical Stage II/III Esophageal Squamous Cell Carcinoma due to Excellent Control of Preoperative Disease and Postoperative Lymph Node Recurrence. Oncology 2017, 92, 221-228. [CrossRef]

37. Liang, D.S.; Zhang, W.J.; Wang, A.T.; Su, H.T.; Zhong, H.J.; Qi, X.R. Treating metastatic triple negative breast cancer with CD44/neuropilin dual molecular targets of multifunctional nanoparticles. Biomaterials 2017, 137, 23-36. [CrossRef]

38. Okines, A.F. T-DM1 in the Neo-Adjuvant Treatment of HER2-Positive Breast Cancer: Impact of the KRISTINE (TRIO-021) Trial. Rev. Recent Clin. Trials 2017. [CrossRef]

39. Schraa, S.J.; Frerichs, K.A.; Agterof, M.J.; Hunting, J.C.B.; Los, M.; de Jong, P.C. Relative dose intensity as a proxy measure of quality and prognosis in adjuvant chemotherapy for breast cancer in daily clinical practice. Eur. J. Cancer 2017, 79, 152-157. [CrossRef]

40. Zhao, G.; Li, Y.; Wang, T. Potentiation of docetaxel sensitivity by miR-638 via regulation of STARD10 pathway in human breast cancer cells. Biochem. Biophys. Res. Commun. 2017, 487, 255-261. [CrossRef]

41. Silva, A.M.; Alvarado, H.L.; Abrego, G.; Martins-Gomes, C.; Garduno-Ramirez, M.L.; Garcia, M.L.; Calpena, A.C.; Souto, E.B. In Vitro Cytotoxicity of Oleanolic/Ursolic Acids-Loaded in PLGA Nanoparticles in Different Cell Lines. Pharmaceutics 2019, 11, 362. [CrossRef] [PubMed]

42. Jose, S.; Fangueiro, J.F.; Smitha, J.; Cinu, T.A.; Chacko, A.J.; Premaletha, K.; Souto, E.B. Cross-linked chitosan microspheres for oral delivery of insulin: Taguchi design and in vivo testing. Colloids Surf. B Biointerfaces 2012, 92, 175-179. [CrossRef] [PubMed]

43. Mattheolabakis, G.; Taoufik, E.; Haralambous, S.; Roberts, M.L.; Avgoustakis, K. In vivo investigation of tolerance and antitumor activity of cisplatin-loaded PLGA-mPEG nanoparticles. Eur. J. Pharm. Biopharm. Off. J. Arb. Pharm. Verfahr. 2009, 71, 190-195. [CrossRef] [PubMed]

44. Andrade, L.N.; Oliveira, D.M.L.; Chaud, M.V.; Alves, T.F.R.; Nery, M.; da Silva, C.F.; Gonsalves, J.K.C.; Nunes, R.S.; Correa, C.B.; Amaral, R.G.; et al. Praziquantel-Solid Lipid Nanoparticles Produced by Supercritical Carbon Dioxide Extraction: Physicochemical Characterization, Release Profile, and Cytotoxicity. Molecules 2019, 24, 3881. [CrossRef]

45. Saxena, V.; Naguib, Y.; Hussain, M.D. Folate receptor targeted 17-allylamino-17-demethoxygeldanamycin (17-AAG) loaded polymeric nanoparticles for breast cancer. Colloids Surf. B Biointerfaces 2012, 94, 274-280. [CrossRef]

46. Ge, Y.; Zhang, Y.; He, S.; Nie, F.; Teng, G.; Gu, N. Fluorescence Modified Chitosan-Coated Magnetic Nanoparticles for High-Efficient Cellular Imaging. Nanoscale Res. Lett. 2009, 4, 287-295. [CrossRef]

47. Pozarowski, P.; Darzynkiewicz, Z. Analysis of cell cycle by flow cytometry. Methods Mol. Biol. 2004, 281, 301-311. [CrossRef]

48. Reddy, N.D.; Shoja, M.H.; Jayashree, B.S.; Nayak, P.G.; Kumar, N.; Prasad, V.G.; Pai, K.S.; Rao, C.M. In vitro and in vivo evaluation of novel cinnamyl sulfonamide hydroxamate derivative against colon adenocarcinoma. Chem. Biol. Interact. 2015, 233, 81-94. [CrossRef] 
49. Wu, W.; Cheng, Y.; Guo, B.H.; Wu, Q. Pharmacokinetics of liver-targeted docetaxel liposomes modified with 6-O-acyl-D-galactose esters in rabbits. Biomed. Rep. 2014, 2, 545-548. [CrossRef]

50. Ritger, P.L.; Peppas, N.A. A simple equation for description of solute release I. Fickian and non-fickian release from non-swellable devices in the form of slabs, spheres, cylinders or discs. J. Control. Release 1987, 5, 23-36. [CrossRef] 